\title{
EXPLORING THE POTENTIAL OF HIGH-RESOLUTION PLANETSCOPE IMAGERY FOR PASTURE BIOMASS ESTIMATION IN AN INTEGRATED CROP-LIVESTOCK SYSTEM
}

\author{
A. A. Dos Reis ${ }^{1,2, *}$, B. C. Silva ${ }^{1}$, J. P. S. Werner ${ }^{1}$, Y. F. Silva ${ }^{1}$, J. V. Rocha ${ }^{1}$, G. K. D. A. Figueiredo ${ }^{1}$, J. F. G. Antunes ${ }^{3}$, J. C. D. M. \\ Esquerdo $^{3}$, A. C. Coutinho ${ }^{3}$, R. A. C. Lamparelli' ${ }^{2}$, P. S. G. Magalhães ${ }^{2}$ \\ ${ }^{1}$ School of Agricultural Engineering - FEAGRI, University of Campinas - UNICAMP, 13083-875 Campinas, Brazil \\ - aareis@unicamp.br, (b261221,j164880,y226147)@dac.unicamp.br, (jansle, gleyce)@unicamp.br \\ ${ }^{2}$ Interdisciplinary Center of Energy Planning - NIPE, University of Campinas - UNICAMP, 13083-896, Campinas, SP, Brazil - \\ (lamparel,graziano)@g.unicamp.br \\ ${ }^{3}$ Embrapa Agricultural Informatics, Brazilian Agricultural Research Corporation - Embrapa, 13083-886, Campinas, SP, Brazil - \\ (joao.antunes, julio.esquerdo, alex.coutinho)@embrapa.br
}

KEY WORDS: Pastureland, Vegetation Indices, Dove satellites, Nano-Satellites, Machine Learning, Random Forest

\begin{abstract}
:
Pasture biomass information is essential to monitor forage resources in grazed areas, as well as to support grazing management decisions. The increasing temporal and spatial resolutions offered by the new generation of orbital platforms, such as Planet CubeSat satellites, have improved the capability of monitoring pasture biomass using remotely-sensed data. In a preliminary study, we investigated the potential of spectral variables derived from PlanetScope imagery to predict pasture biomass in an area of Integrated Crop-Livestock System (ICLS) in Brazil. Satellite and field data were collected during the same period (May - August 2019) for calibration and validation of the relation between predictor variables and pasture biomass using the Random Forest (RF) regression algorithm. We used as predictor variables 24 vegetation indices derived from PlanetScope imagery, as well as the four PlanetScope bands, and field management information. Pasture biomass ranged from approximately 24 to $656 \mathrm{~g} . \mathrm{m}^{-2}$, with a coefficient of variation of 54.96\%. Near Infrared Green Simple Ratio (NIR/Green), Green Leaf Algorithm (GLA) vegetation indices and days after sowing (DAS) are among the most important variables as measured by the RF Variable Importance metric in the best RF model predicting pasture biomass, which resulted in Root Mean Square Error (RMSE) of 52.04 g.m ${ }^{-2}$ (32.75\%). Accurate estimates of pasture biomass using spectral variables derived from PlanetScope imagery are promising, providing new insights into the opportunities and limitations related to the use of PlanetScope imagery for pasture monitoring.
\end{abstract}

\section{INTRODUCTION}

Monitoring pasture biomass is fundamental to understand the spatio-temporal dynamics of forage resources in grazed areas, and to support grazing management decisions (Andersson et al., 2017). Pasture monitoring at a fine scale based on field measurements are time-consuming and often spatially-limited based on sampling point distribution and intensity, and unlikely to give representative information of large pasture areas (Legg and Bradley, 2019).

An alternative approach to estimate pasture biomass is utilizing remotely-sensed data (Punalekar et al., 2018). Pasture biomass estimation based on remote sensing has been undertaken for several years, and numerous studies show a good correlation between field measurements and spectral variables derived from satellite data (Edirisinghe et al., 2011; Pullanagari et al., 2018; Wang et al., 2019). However, the temporal frequency of satellite data and the spatial resolution needed to capture the biomass variation between or within typical-sized paddocks $(<20 \mathrm{ha})$ have been an obstacle to achieve effective pasture monitoring using the available satellite data sources, namely MODIS (250 m near daily from 2000), Landsat 8 OLI (30 m every 16 days from 2013) and Sentinel-2 (10 m every 5 days from 2015).

The increasing temporal and spatial resolution offered by the new generation of satellites, so-called constellations of nano- satellites, such as Planet CubeSat satellites, may overcome this spatio-temporal limitation by using multiple small satellites to collect global high spatial resolution data with very high temporal resolution. Furthermore, these nano-satellites may advance the field of crop monitoring by offering an unprecedented combination of high temporal (daily) and high spatial (3 meters) resolutions imagery (Planet Team, 2019).

Machine learning algorithms have been increasingly used for a wide range of tasks including pasture monitoring (Parente et al., 2017, Liu et al., 2019, Wang et al., 2019). In this context, using the Random Forest (RF) machine learning algorithm, we investigated the potential of spectral variables (spectral bands and vegetation indices) derived from PlanetScope imagery associated with field management information to predict pasture biomass in an area of Integrated Crop-Livestock System (ICLS) in the western region of São Paulo State, Brazil

\section{METHODOLOGY}

\subsection{Study area}

Our study area includes four fields of approximately 50 ha each, totalizing 200 ha, located in the western region of São Paulo State, Brazil (Figure 1). The area is split in 13 paddocks on which grazing livestock (cattle) are rotated between paddocks and fields throughout the season. This area has been managed as an ICLS

\footnotetext{
* Corresponding author
} 
based on the rotation of cultivated pasture during the winter season, and soybean cultivation in the summer season, with pasture being the focus of this study.

The investigated pasture is composed of a mixture of brachiaria (Urochloa ruziziensis) and millet (Pennisetum glaucum), sown at a proportion of $15 \mathrm{~kg} \cdot \mathrm{ha}^{-1}$ of millet and $5 \mathrm{~kg} \cdot \mathrm{ha}^{-1}$ of brachiaria in a spacing of $17 \mathrm{~cm}$ between rows. Pasture planting began on March $28^{\text {th }}$, after soybean harvest, and lasted until $6^{\text {th }}$ April 2019.

According to the Köppen climatic classification system, the climate in this region is Aw, classified as a tropical savanna, with drier months during the winter (Alvares et al., 2013). The mean annual rainfall varies between $1,200 \mathrm{~mm}$ to $1,400 \mathrm{~mm}$, concentrated in the months of December and January.

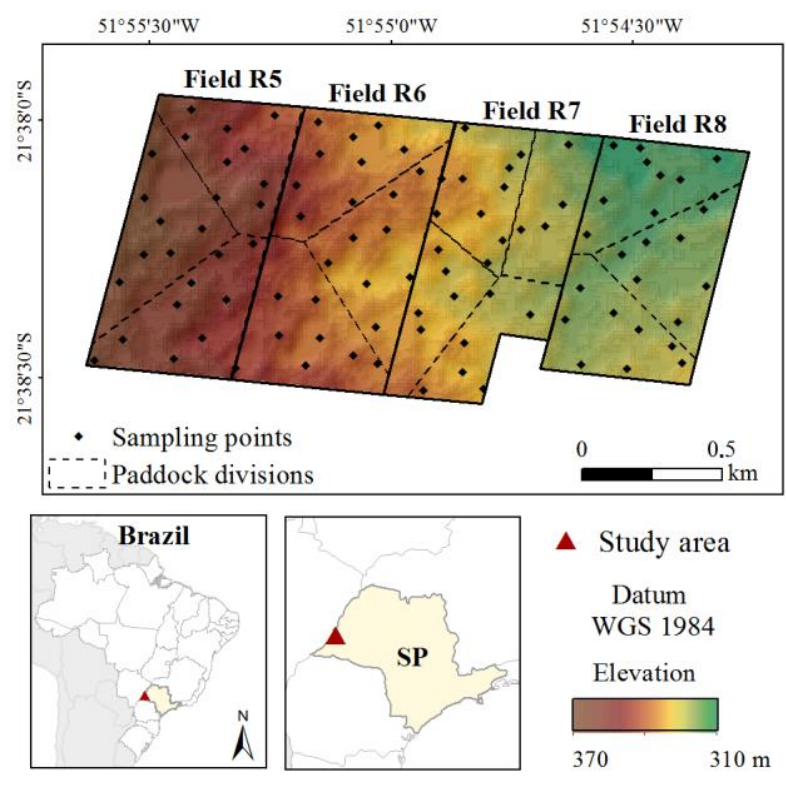

Figure 1. Location of the study area in western region of São Paulo (SP) state, Brazil, and the sampling design.

\subsection{Field data collection}

One hundred sampling points were randomly distributed within the study area. In each of these points, pasture biomass was manually harvested based in a frame of $1 \times 1 \mathrm{~m}$. The fresh biomass was weighted in the field using a hanging scale. To determine dry mass $\left(\mathrm{g} . \mathrm{m}^{-2}\right)$, the fresh biomass was dried at $65^{\circ} \mathrm{C}$ in the laboratory for 72 hours.

Measurements of on-site pasture biomass were conducted at five dates (designated from now on as Date 1 to Date 5) during the growing season (from May to August of 2019): (Date 1) $17^{\text {th }}$ May, (Date 2) $25^{\text {th }}$ May, (Date 3) $18^{\text {th }}$ June, (Date 4) $14^{\text {th }}$ July, and (Date 5) $12^{\text {th }}$ August 2019. These dates were defined in order to capture different phases of pasture growth and biomass availability, as well as in function of the entry and exit of animals in the paddocks. The field measurement dates and the numbers of sampling points measured in each field campaign varied according to paddock rotation, totalizing 288 field-sampled points.

\subsection{Remote sensing data collection and preprocessing}

PlanetScope multispectral imagery were acquired for this study. The selected cloud-free scenes covering the study area were acquired on dates that most closely coincided with the field campaign dates (i.e., $20^{\text {th }}$ May 2019, $27^{\text {th }}$ May 2019, $15^{\text {th }}$ June $2019,11^{\text {th }}$ July 2019 , and $10^{\text {th }}$ August 2019, respectively).

PlanetScope is a satellite constellation comprising over 120 CubeSats $3 U$ form factor $(10 \mathrm{~cm}$ by $10 \mathrm{~cm}$ by $30 \mathrm{~cm})$, called "Doves", which have the capability to image all of the Earth's land surface on a daily basis. The PlanetScope satellites have four spectral bands: blue (B: $455-515 \mathrm{~nm})$, green (G: $500-590 \mathrm{~nm}$ ), red (R: 590-670 nm) and near infrared (NIR: 780-860 nm) with a spatial resolution of $\sim 3 \mathrm{~m}$ (Planet Team, 2019).

We used the Planet Surface Reflectance (SR) Product, which is derived from the standard Planet Analytic Product (Radiance) and processed to top of atmosphere (TOA) reflectance and then atmospherically corrected to bottom of atmosphere (BOA) reflectance using the 6SV2.1 radiative transfer code (Planet Team, 2018).

In order to explore the potential of PlanetScope derived spectral variables in the prediction of pasture biomass, we calculated 24 vegetation indices that only include visible and NIR spectral bands on their formulation (Table 1).

\subsection{Random forest regression algorithm}

Vegetation indices, spectral bands, field and paddock identification, and days after sowing (DAS) information were used to predict pasture biomass in this study. We used the RF machine learning algorithm (Breiman, 2001) to model and map pasture biomass. The 288 field-sampled points were randomly divided into $70 \%$ (202 points) and 30\% (86 points) for training and validation of the RF models, respectively.

We first performed a feature selection using the FSelector $\mathrm{R}$ package (Cheng et al., 2012) to select a subset of predictor variables that were most informative for predicting pasture biomass. Next, we fitted a RF model. Then, to determine the optimal parameters, number of trees (ntree) in the forest and the number of variables randomly sampled at each note (mtry), we tuned the parameters using 10 -fold cross validation.

Finally, we evaluated the variable importance (VI) in the best performing RF model by calculating the percentage of increase in the mean square error (incMSE), which reflects the importance of each predictor in the prediction accuracy of pasture biomass. All RF analyses were performed using the R software package $m l r$ (R Core Team, 2018).

\subsection{Accuracy assessment}

The accuracies of predicted pasture biomass were evaluated using the Root Mean Square Error (RMSE) calculated based on field-based pasture biomass measurements in the validation dataset, as described in Equations (1) and (2).

$$
\begin{aligned}
& R M S E=\sqrt{\sum_{i=1}^{n} \frac{\left(X_{i}-\widehat{X}_{i}\right)^{2}}{n}} \\
& \operatorname{RMSE}(\%)=\frac{R M S E}{\bar{X}} \times 100
\end{aligned}
$$

where $\quad n=$ the number of observations in the dataset

$\widehat{X}_{i}, X_{i}=$ estimated and observed pasture biomass value in the validation dataset, respectively

$\bar{X}=$ the mean value of pasture biomass in the validation dataset 


\begin{tabular}{|c|c|c|c|}
\hline Index & Name & Formula & Reference \\
\hline ARVI & $\begin{array}{l}\text { Atmospherically Resistant } \\
\text { Vegetation Index }\end{array}$ & $(\mathrm{NIR}-2 \mathrm{R}+\mathrm{B}) /(\mathrm{NIR}+2 \mathrm{R}-\mathrm{B})$ & $\begin{array}{c}\text { (Kaufman and Tanre, } \\
1992)\end{array}$ \\
\hline BGND & Blue Green Normalized Difference & $(G-B) /(G+B)$ & - \\
\hline DVI & Difference Vegetation Index & NIR - R & (Tucker, 1979) \\
\hline EVI & Enhanced Vegetation Index & $2.5((\mathrm{NIR}-\mathrm{R}) /(\mathrm{NIR}+6 \mathrm{R}-7.5 \mathrm{~B}+1)$ & (Huete et al., 2002) \\
\hline EVI2 & Enhanced Vegetation Index 2 & $(2.5(\mathrm{NIR}-\mathrm{R})) /(1+\mathrm{NIR}+2.4 \mathrm{R})$ & (Jiang et al., 2008) \\
\hline ExB & Excess Blue Vegetation Index & $1.4 \mathrm{~B}-\mathrm{G}$ & (Mao et al., 2013) \\
\hline ExG & Excess Green Vegetation Index & $2 \mathrm{G}-\mathrm{R}-\mathrm{B}$ & (Woebbecke et al., 1995) \\
\hline ExGR & $\begin{array}{c}\text { Excess Green minus Excess Red } \\
\text { Vegetation Index }\end{array}$ & ExG - ExR & Neto et al. (2004) \\
\hline ExR & Excess Red Vegetation Index & $1.4 \mathrm{R}-\mathrm{G}$ & (Meyer and Neto, 2008) \\
\hline GLA & Green Leaf Algorithm & $(2 G-R-B) /(2 G+R+B)$ & (Louhaichi et al., 2001) \\
\hline GNDVI & $\begin{array}{l}\text { Green Normalized Difference } \\
\text { Vegetation Index }\end{array}$ & $(\mathrm{NIR}-\mathrm{G}) /(\mathrm{NIR}+\mathrm{G})$ & (Huete et al., 2002) \\
\hline GRVI & Green Ratio Vegetation Index & $\mathrm{G} / \mathrm{R}$ & (Kanemasu, 1974) \\
\hline IPVI & $\begin{array}{l}\text { Infrared Percentage Vegetation } \\
\text { Index }\end{array}$ & NIR/(NIR + R) & (Crippen, 1990) \\
\hline MGRDI & $\begin{array}{l}\text { Modified Green Red Vegetation } \\
\text { Index }\end{array}$ & $\left(G^{2}-R^{2}\right) /\left(G^{2}+R^{2}\right)$ & (Tucker, 1979) \\
\hline MSAVI & $\begin{array}{c}\text { Modified Soil-Adjusted Vegetation } \\
\text { Index }\end{array}$ & {$\left[(2 \mathrm{NIR}+1)-\sqrt{(2 \mathrm{NIR}+1)^{2}-8(\mathrm{NIR}-\mathrm{R})}\right] / 2$} & (Qi et al., 1994) \\
\hline NDVI & $\begin{array}{c}\text { Normalized Difference Vegetation } \\
\text { Index }\end{array}$ & $(\mathrm{NIR}-\mathrm{R}) /(\mathrm{NIR}+\mathrm{R})$ & Rouse et al. (1973) \\
\hline NGRDI & $\begin{array}{l}\text { Normalized Green-Red Difference } \\
\text { Index }\end{array}$ & $(G-R) /(G+R)$ & (Tucker, 1979) \\
\hline NIR/GREEN & NIR Green Simple Ratio & $\mathrm{G} / \mathrm{R}$ & - \\
\hline OSAVI & $\begin{array}{l}\text { Optimized Soil-Adjusted Vegetation } \\
\text { Index }\end{array}$ & $(\mathrm{NIR}-\mathrm{R}) /(\mathrm{NIR}+\mathrm{R}+0.16)$ & (Rondeaux et al., 1996) \\
\hline RGBVI & Red Green Blue Vegetation Index & $\left(G^{2}-B^{*} R\right) /\left(G^{2}+B^{*} R B\right)$ & (Bendig et al., 2015) \\
\hline RVI & Ratio Vegetation Index & $\mathrm{R} / \mathrm{NIR}$ & $\begin{array}{l}\text { Richardson and Wiegand } \\
\text { (1977) }\end{array}$ \\
\hline SAVI & Soil-Adjusted Vegetation Index & {$[(\mathrm{NIR}-\mathrm{R}) /(\mathrm{NIR}+\mathrm{R}+0.5)] \cdot(1+0.5)$} & (Huete, 1988) \\
\hline SR & Simple Ratio & $\mathrm{NIR} / \mathrm{R}$ & (Jordan, 1969) \\
\hline VARI & $\begin{array}{l}\text { Visible Atmospherically } \\
\text { Resistant Index }\end{array}$ & $(\mathrm{G}-\mathrm{R}) /(\mathrm{G}+\mathrm{R}-\mathrm{B})$ & (Gitelson et al., 2002) \\
\hline
\end{tabular}

Table 1. Summary of the vegetation indices (VIs) used in this study for pasture biomass estimation.

Next, we mapped the predicted pasture biomass for the entire study area for four months of the pasture-growing season (May, June, July, and August)

\section{RESULTS}

Pasture biomass varied from 24.04 to 656.08 g.m $\mathrm{m}^{-2}$, with an overall mean value of $156.82 \mathrm{~g} . \mathrm{m}^{-2}$ for all sampling dates, resulting in a high variability of the pasture biomass in the study area (coefficient of variation equal to $54.96 \%$ ). The sampling dates of May (Date 1 and Date 2) exhibited the highest mean pasture biomass (mean value of 189.48 g.m. ${ }^{-2}$ ), whereas Date 4 showed the lowest mean biomass $\left(102.74 \mathrm{~g} . \mathrm{m}^{-2}\right)$.

The best RF model to predict pasture biomass based on spectral variables extracted from PlanetScope imagery as well as paddock identification and DAS data resulted in an accuracy of approximately $56 \%$ (coefficient of determination $\left(\mathrm{R}^{2}\right)=55.65 \%$ ) and a relatively low RMSE (52.04 g. $\mathrm{m}^{-2}$ or $32.75 \%$ ), based on the validation dataset. Figure 2 shows a comparison of measured versus predicted pasture biomass, where values closer to the axis of $45^{\circ}$ indicate higher accuracy.

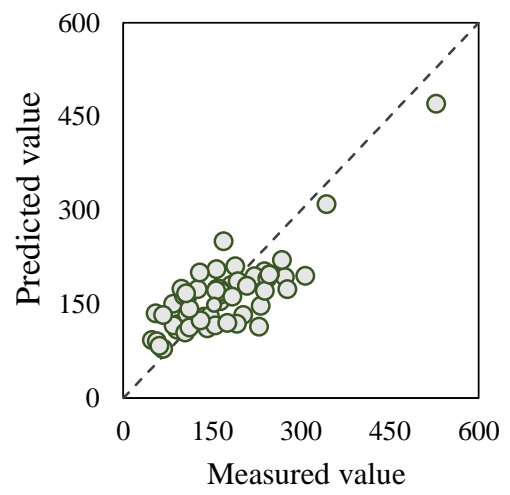

Figure 2. Scatterplots of the predicted versus measured values of pasture biomass $\left(\mathrm{g} \cdot \mathrm{m}^{-2}\right)$ in the validation dataset. 
Using RF Variable Importance, NIR/Green, GLA, IPVI vegetation indices, DAS, and NIR band are among the most important variables to predict pasture biomass in our study (Figure 3).

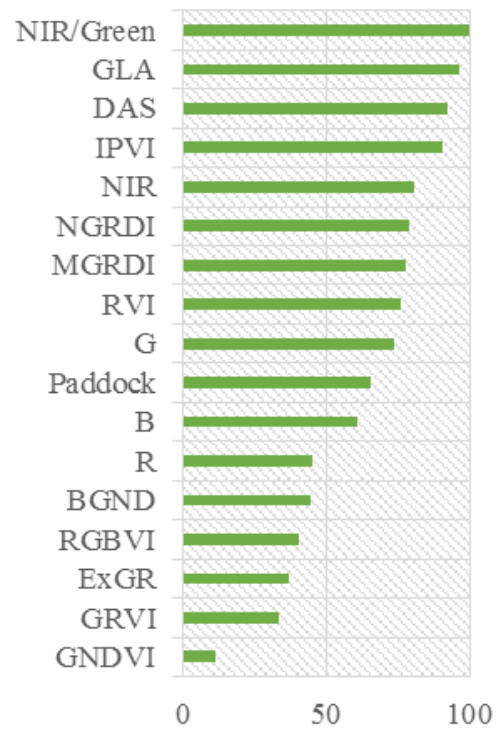

Relative Importance (\%)

Figure 3. Relative importance of the variables as measured by the Variable Importance metric in the Random Forest algorithm.

The predicted pasture biomass maps for our study area for four dates $-20^{\text {th }}$ May, $15^{\text {th }}$ June, $11^{\text {th }}$ July, and $10^{\text {th }}$ August 2019, are shown in Figure 4. These maps show spatio-temporal changes in pasture biomass for all paddocks, which were in parity with expected changes in pasture vegetation, as driven by forage development and management operations.
Grazing commenced on the paddocks of Field R5 and R6 in 17 ${ }^{\text {th }}$ May 2019, and on the paddocks of Field R7 and R8 in 27 May and $31^{\text {th }}$ May 2019, respectively. Paddock grazing approximately followed a rotational pattern from May to the middle of June, when all animals were removed from the paddocks. The paddocks remained animal-free until the first dekad of August. The paddock management operations resulted in pronounced differences in pasture biomass production during the growing season, which could be clearly seen in the pasture biomass maps produced for the four different dates between May and August (Figure 4).

\section{DISCUSSIONS}

Since the proposal of Planet's constellation of CubeSats, these nano-satellites have offered an unprecedented opportunity to monitor vegetation dynamics with enhanced spatial detail more frequently than ever before (Helman et al., 2018; Miller et al., 2019). In this preliminary study, our results demonstrated the capacity of spectral variables derived from PlanetScope imagery to monitor pasture biomass at high spatial $(\sim 3 \mathrm{~m})$ and temporal ( daily) resolution.

The seasonal dynamics of forage production in our study area are influenced by changes in the proportion of millet and brachiaria, environmental conditions, and grazing management, which resulted in greater variation in the spatio-temporal pattern of pasture biomass in the fields during the growing season. The highest values of pasture biomass (> $500 \mathrm{~g} . \mathrm{m}^{-2}$ ) observed in the predicted maps in the month of May can be explained by the good initial growth of millet in the begging of the pasture-growing season. Later in the growing season, in the months of June and July, all paddocks had lower values of pasture biomass due to grazing and plant water stress, a meteorological drought characteristic in this region during the winter months (total precipitation in June-July equals to $56.7 \mathrm{~mm}$ ).

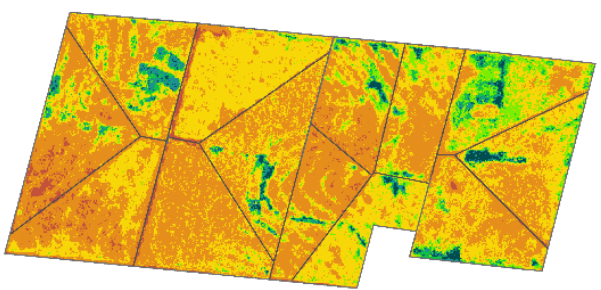

(a)

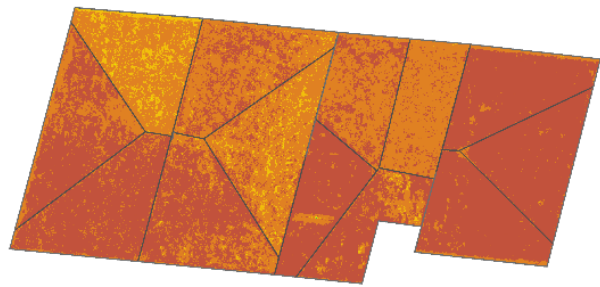

(c)

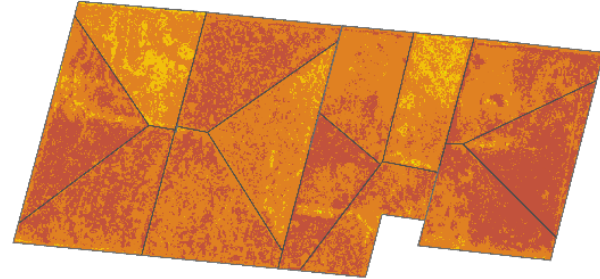

(b)

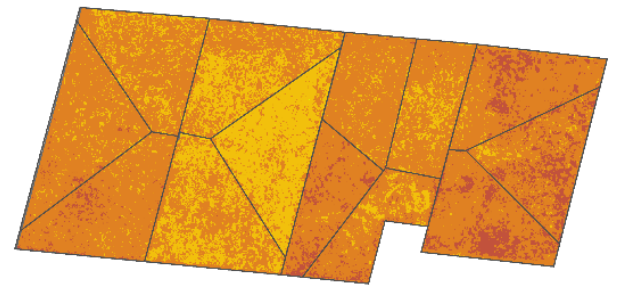

(d)

\section{Pasture biomass (g.m $\left.{ }^{-2}\right)$}

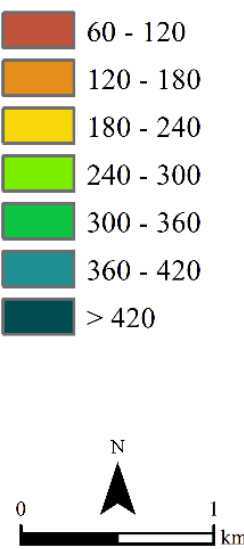

Figure 4. Pasture biomass spatial maps predicted by the best RF model for the study area in four dates: (a) $20^{\text {th }}$ May 2019 , (b) $15^{\text {th }}$ June 2019, (c) $11^{\text {th }}$ July 2019, and (d) $10^{\text {th }}$ August 2019. 
Several studies have used vegetation indices, especially NDVI and EVI, derived from MODIS $(250 \mathrm{~m})$ and Landsat $(30 \mathrm{~m})$ images, and more recently from Sentinel-2 $(10 \mathrm{~m})$ to captured the seasonality of grazing pastures ( $\mathrm{Gu}$ and Wylie, 2015; Vrieling et al., 2016; Wang et al., 2019). In this study, we found that the VIs and the spectral bands from PlanetScope imagery were consistently able to detect the seasonality of pasture biomass at a finer spatial resolution. On the other hand, our best RF model resulted in overestimation at low pasture biomass levels and underestimation of pasture biomass greater than $\sim 300$ g.m $\mathrm{m}^{-2}$ (Figure 2).

The moderate performance of our model $\left(\mathrm{R}^{2}=55.65 \%\right)$ could be explained by the high inter-paddock and intra-paddock variation in pasture production due to other factors not particularly considered in this study, such as heterogeneous soil characteristics and terrain variation, as well as, the radiometric data quality of PlanetScope imagery (Houborg and McCabe, 2016). While the new generation of orbital platforms offers an unprecedented combination of high temporal and spatial resolution imagery, these satellites have the disadvantage of not being equivalent to a rigorously calibrated and high performing satellite such as Landsat 8 (Houborg and McCabe, 2018). In addition, these satellites can also present cross-sensor variations that may affect the relationship between field-based pasture biomass and spectral variables derived from PlanetScope imagery.

In this preliminary study, our intention was to explore the potential of spectral variables derived from PlanetScope imagery to assess and monitor pasture biomass, as well as to identify possible limitations of using these images for pasture monitoring. Despite possible limitations, we believe that our results are encouraging and should motivate further investigations for using PlanetScope imagery to assess and monitor pasture biomass.

\section{CONCLUSIONS}

This study evaluated the potential of spectral variables (vegetation indices and spectral bands) derived from PlanetScope imagery to predict pasture biomass when associated with field management information using the Random Forest (RF) machine learning algorithm.

Since pasture biomass production and availability vary seasonally and are influenced especially by environmental conditions and grazing management, our results showed that by combining PlanetScope imagery and field management information, we were able to predict the spatio-temporal changes in pasture biomass with a relatively low RMSE (32.75\%).

Accurately estimating pasture biomass using spectral variables derived from PlanetScope imagery are promising, providing new insights into the opportunities and limitations related to the use of PlanetScope imagery for pasture monitoring.

\section{ACKNOWLEDGEMENTS}

The authors would like to thank FAPESP (Process 2017/502059) for the financial support and for the fellowship granted to A. A. Dos Reis (Process 2018/24985-0). We also would like to thank CAPES (Finance Code 001) and CNPq for the fellowships granted to B. C. Silva, J. P. S. Werner, Y. F. Silva, respectively.

\section{REFERENCES}

Alvares, C.A., Stape, J.L., Sentelhas, P.C., Gonçalves, J.L.M., Sparovek, G., 2013. Köppen's climate classification map for Brazil. Meteorologische Zeitschrift, 22(6), 711-728. doi:10.1127/0941-2948/2013/0507

Andersson, K., Trotter, M., Robson, A., Schneider, D., Frizell, L., Saint, A., Lamb, D., Blore, C., 2017. Estimating pasture biomass with active optical sensors. Adv. Anim. Biosci. 8, 754757. https://doi.org/10.1017/s2040470017000838

Bendig, J., Yu, K., Aasen, H., Bolten, A., Bennertz, S., Broscheit, J., Gnyp, M.L., Bareth, G., 2015. Combining UAV-based plant height from crop surface models, visible, and near infrared vegetation indices for biomass monitoring in barley. Int. J. Appl. Earth Obs. Geoinf. 39, 79-87. https://doi.org/10.1016/ j.jag.2015.02.012

Breiman, L., 2001. Random Forests. Mach. Learn. 45, 5-32. https://doi.org/10.1023/A:1010933404324

Cheng, T., Wang, Y., Bryant, S.H., 2012. FSelector: a Ruby gem for feature selection. Bioinformatics 28, 2851-2852. https://doi.org/10.1093/bioinformatics/bts528

Crippen, R., 1990. Calculating the vegetation index faster. Remote Sens. Environ. 34, 71-73. https://doi.org/10.1016/00344257(90)90085-Z

Edirisinghe, A., Hill, M.J., Donald, G.E., Hyder, M., 2011. Quantitative mapping of pasture biomass using satellite imagery. Int. J. Remote Sens. 32, 2699-2724. https://doi.org/ $10.1080 / 01431161003743181$

Gitelson, A.A., Kaufman, Y.J., Stark, R., Rundquist, D., 2002. Novel algorithms for remote estimation of vegetation fraction. Remote Sens. Environ. 80, 76-87. https://doi.org/10.1016/S00344257(01)00289-9

Gu, Y., Wylie, B.K., 2015. Developing a 30-m grassland productivity estimation map for central Nebraska using 250-m MODIS and 30-m Landsat-8 observations. Remote Sens. Environ. 171, 291-298.https://doi.org/10.1016/j.rse.2015.10.018

Helman, D., Bahat, I., Netzer, Y., Ben-Gal, A., Alchanatis, V., Peeters, A., Cohen, Y., 2018. Using time series of high-resolution planet satellite images to monitor grapevine stem water potential in commercial vineyards. Remote Sens. 10, 1615. https://doi.org/10.3390/rs10101615

Houborg, R., McCabe, M.F., 2018. A Cubesat enabled SpatioTemporal Enhancement Method (CESTEM) utilizing Planet, Landsat and MODIS data. Remote Sens. Environ. 209, 211-226. https://doi.org/10.1016/j.rse.2018.02.067

Houborg, R., McCabe, M.F., 2016. High-Resolution NDVI from planet's constellation of earth observing nano-satellites: A new data source for precision agriculture. Remote Sens. 8. https://doi.org/10.3390/rs8090768

Huete, A., 1988. A soil-adjusted vegetation index (SAVI). Remote Sens. Environ. 25, 295-309. https://doi.org/10.1016/0034-4257(88)90106-X

Huete, A., Didan, K., Miura, T., Rodriguez, E., Gao, X., Ferreira, L., 2002. Overview of the radiometric and biophysical 
performance of the MODIS vegetation indices. Remote Sens. Environ. $\quad 83$, 195-213. https://doi.org/10.1016/S00344257(02)00096-2

Jiang, Z., Huete, A., Didan, K., Miura, T., 2008. Development of a two-band enhanced vegetation index without a blue band Remote Sens. Environ. 112, 3833-3845. https://doi.org/10.1016/j.rse.2008.06.006

Jordan, C.F., 1969. Derivation of Leaf-Area Index from Quality of Light on the Forest Floor. Ecology 50, 663-666. https://doi.org/10.2307/1936256

Kanemasu, E.T., 1974. Seasonal canopy reflectance patterns of wheat, sorghum, and soybean. Remote Sens. Environ. 3, 43-47. https://doi.org/10.1016/0034-4257(74)90037-6

Kaufman, Y.J., Tanre, D., 1992. Atmospherically resistant vegetation index (ARVI) for EOS-MODIS. IEEE Trans. Geosci. Remote Sens. 30, 261-270. https://doi.org/10.1109/36.134076

Legg, M., Bradley, S., 2019. Ultrasonic proximal sensing of pasture biomass. Remote Sens. 11, 2459. https://doi.org/10.3390/rs11202459

Liu, Y., Gong, W., Xing, Y., Hu, X., Gong, J., 2019. Estimation of the forest stand mean height and aboveground biomass in Northeast China using SAR Sentinel-1B, multispectral Sentinel2A, and DEM imagery. ISPRS J. Photogramm. Remote Sens. 151, 277-289. https: doi:10.1016/j.isprsjprs.2019.03.016

Louhaichi, M., Borman, M.M., Johnson, D.E., 2001. Spatially located platform and aerial photography for documentation of grazing impacts on wheat. Geocarto Int. 16, 65-70. https://doi.org/10.1080/10106040108542184

Mao, W., Wang, Yiming, Wang, Yueqing, 2013. Real-time detection of between-row weeds using machine vision, in: 2003, Las Vegas, NV July 27-30, 2003. American Society of Agricultural and Biological Engineers, St. Joseph, MI. https://doi.org/10.13031/2013.15381

Meyer, G.E., Neto, J.C., 2008. Verification of color vegetation indices for automated crop imaging applications. Comput. Electron. Agric. 63, 282-293. https://doi.org/10.1016/j.compag. 2008.03.009

Miller, G.J., Morris, J.T., Wang, C., 2019. Estimating aboveground biomass and its spatial distribution in coastal wetlands utilizing planet multispectral imagery. Remote Sens. 11, 2020. https://doi.org/10.3390/rs11172020

Neto, J.C. A combined statistical-soft computing approach for classification and mapping weed species in minimum -tillage systems. Ph.D. Thesis, University of Nebraska - Lincoln, Lincoln, NE, USA, August 2004.

Parente, L., Ferreira, L., Faria, A., Nogueira, S., Araújo, F., Teixeira, L., Hagen, S., 2017. Monitoring the Brazilian pasturelands: A new mapping approach based on the Landsat 8 spectral and temporal domains. Int. J. Appl. Earth Obs. Geoinf. 62, 135-143. http://dx.doi.org/10.1016/j.jag.2017.06.003.

Planet Team, 2018. Planet Surface Reflectance. https://assets.planet.com/marketing/PDF/Planet_Surface_Reflec tance_Technical_White_Paper.pdf (20 October 2019).
Planet Team, 2019. Planet Imagery Product Specifications https://assets.planet.com/docs/combined-imagery-product-specfinal-august-2019.pdf (20 October 2019).

Pullanagari, R., Kereszturi, G., Yule, I., 2018. Integrating airborne hyperspectral, topographic, and soil data for estimating pasture quality using recursive feature elimination with random forest regression. Remote Sens. 10, 1117. https://doi.org/10.3390/rs10071117

Punalekar, S.M., Verhoef, A., Quaife, T.L., Humphries, D., Bermingham, L., Reynolds, C.K., 2018. Application of Sentinel2A data for pasture biomass monitoring using a physically based radiative transfer model. Remote Sens. Environ. 218, 207-220. https://doi.org/10.1016/j.rse.2018.09.028

Qi, J., Chehbouni, A., Huete, A.R., Kerr, Y.H., Sorooshian, S., 1994. A modified soil adjusted vegetation index. Remote Sens. Environ. 48, 119-126. https://doi.org/10.1016/00344257(94)90134-1

R Core Team. 2018. R: A language and environment for statistical computing. Vienna: R Foundation for Statistical Computing.

Richardson, A.J., Wiegand, C.L, 1977. Distinguishing vegetation from soil background information. Photogramm. Eng. Rem. S. $43,1541-1552$.

Rondeaux, G., Steven, M., Baret, F., 1996. Optimization of soiladjusted vegetation indices. Remote Sens. Environ. 55, 95-107. https://doi.org/10.1016/0034-4257(95)00186-7

Rouse J, Haas R, Schell J, Deering D, Harlan J. Monitoring vegetation systems in the Great Plains with ERTS. In: Third Earth Resources Technology Satellite-1 Symposium, Washington, D.C.: NASA SP-351, v.1, p.309-317, 1973.

Tucker, C.J., 1979. Red and photographic infrared linear combinations for monitoring vegetation. Remote Sens. Environ. 8, 127-150. https://doi.org/10.1016/0034-4257(79)90013-0

Vrieling, A., Meroni, M., Mude, A.G., Chantarat, S., Ummenhofer, C.C., de Bie, K.C.A.J.M., 2016. Early assessment of seasonal forage availability for mitigating the impact of drought on East African pastoralists. Remote Sens. Environ. 174, 44-55. https://doi.org/10.1016/j.rse.2015.12.003

Wang, J., Xiao, X., Bajgain, R., Starks, P., Steiner, J., Doughty, R.B., Chang, Q., 2019. Estimating leaf area index and aboveground biomass of grazing pastures using Sentinel-1, Sentinel-2 and Landsat images. ISPRS J. Photogramm. Remote Sens. 154, 189-201. https://doi.org/10.1016/j.isprsjprs.2019.06. 007

Woebbecke, D. M., Meyer, G. E., Von Bargen, K., Mortensen, D. A., 1995. Color indices for weed identification under various soil, residue, and lighting conditions. Trans. ASAE 38, 259-269. https://doi.org/10.13031/2013.27838 